\title{
LIFE HISTORY OF DYNASTOR DARIUS \\ (LEPIDOPTERA: NYMPHALIDAE: BRASSOLINAE) \\ IN PANAMA
}

\author{
ByAnnette Aiello and Robert E. Silberglied* \\ Smithsonian Tropical Research Institute \\ P.O. Box 2072, Balboa, Panama
}

\begin{abstract}
Dynastor darius (Fabr.) (Figure 1) ${ }^{1}$ is a large crepuscular butterfly found from Guatemala south into Brasil(Blandin, 1976; Blandin and Descimon, 1977). The larva is known to feed on various bromeliads. In the interests of amplifying the scattered and fragmentary descriptions of the immature stages by previous workers, and commenting upon certain discrepancies between their findings and our own, we here present data on twelve individuals of Dynastor darius reared on Barro Colorado Island (BCI), Panama in 1978.
\end{abstract}

On 21 June we captured a female of Dynastor darius, and over the period 23-25 June obtained twelve eggs (Figure 2). These were spherical, $2.2 \mathrm{~mm}$ in diameter, and cream colored with a pattern of anastomosing striae oriented from pole to pole. The first instars emerged eleven days after oviposition and we presented them with leaves of a variety of monocot species: Musa paradisiaca (Musaceae), Heliconia sp. (Heliconiaceae), Monstera sp. (Araceae), Cocos nucifera (Palmae), Zingiber sp. (Zingiberaceae), Philodendron tripartitum (Araceae), Ananas comosus (Bromeliaceae), and an unidentified grass (Gramineae). The larvae ate only the pineapple (Ananas comosus).

\section{FIRST INSTAR LARVAE}

Newly hatched larvae were $7.6-8 \mathrm{~mm}$ in length excluding the caudae, which were $2 \mathrm{~mm}$ long, orange on the basal half and black apically. At the tip, each cauda bore a $1 \mathrm{~mm}$ long seta which was black on the basal half and white apically, plus several appressed setae toward the base. The tip of the body between the caudae was red. The

\footnotetext{
* Present address: Museum of Comparative Zoology, Harvard University, Cambridge, Massachusetts, U.S.A. 02138.

Manuscript received by the editor February 26, 1979.

'Figures 1 and 11 represent the individual in rearing Lot 78-75. Figures 2-10 represent the twelve individuals in rearing Lot $78-84$.
} 


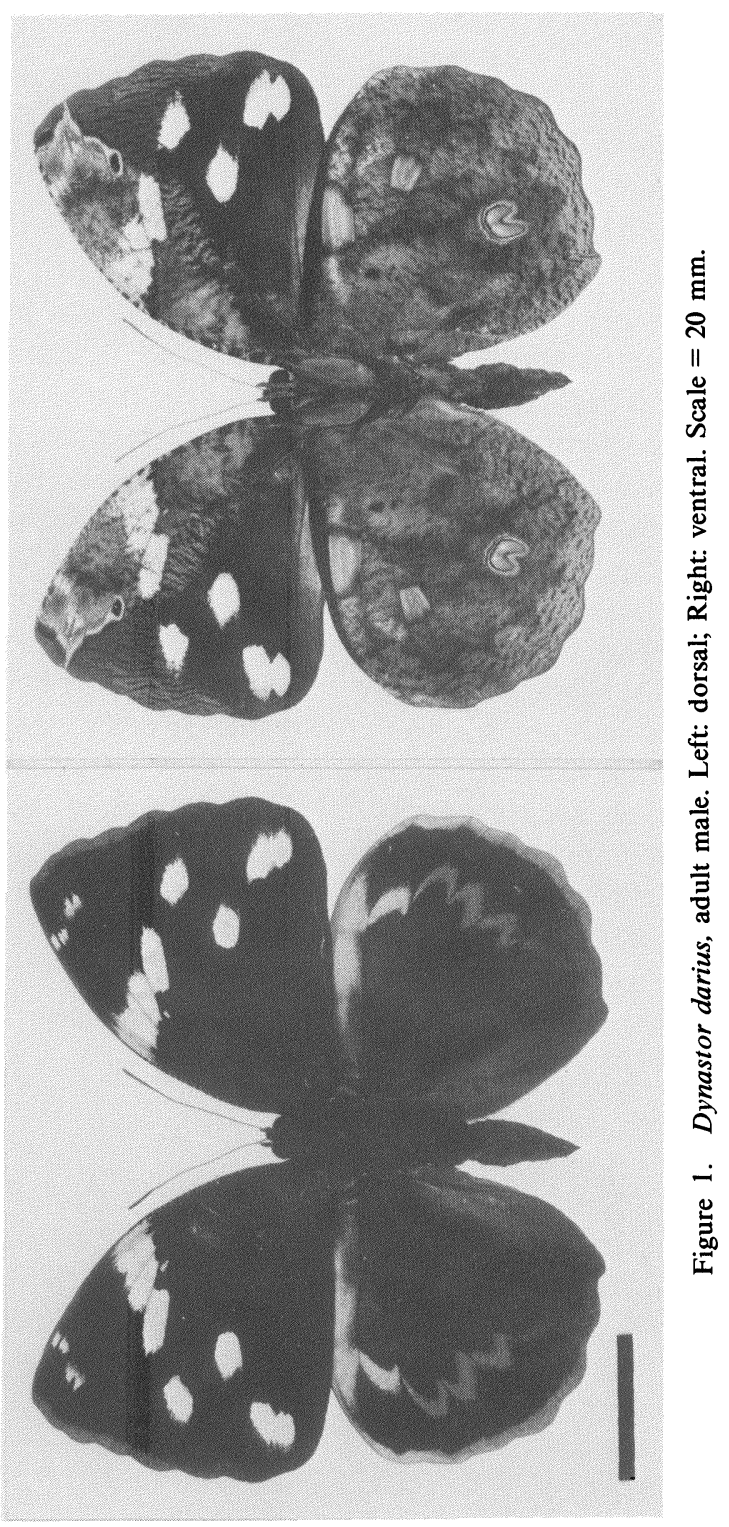


head capsule (Figure 9, A and B) displayed a complex pattern of beige, brown, and black, almost obscured by a dense covering of 1 $\mathrm{mm}$ long black, plumose setae. Four pairs of low bumps marked the positions where horns appeared in the second instar.

Before taking their first meal, each larva (Figure 4) had a redbrown dorsal stripe plus four yellow and three red-brown lateral stripes, and an oval red dorsal spot (Figure 7A) between abdominal segments 3 and 4 . After feeding and expanding, the larval stripes (Figure 5) became green and yellow, with several extra yellow stripes appearing between old ones. The dorsal spot became black, flanked on the sides with red and orange, and bordered on each end with orange and white (Figure 7B). A second and much smaller dorsal spot, white at the anterior end and black posteriorly, appeared between abdominal segments 5 and 6 . The positions of these spots correspond to positions $6-7$, and 8-9 of the system used by Burmeister (1873) and Müller (1886) who numbered thoracic and abdominal segments as one series.

A pinkish red eversible gland (Figure 3), located ventrally on the prothorax between the legs and head, became particularly evident in later instars. When disturbed, larvae reared up and waved from side to side, emitting a pineapple-like odor that seemed to come from the large everted gland.

\section{FurTher LARVAL DEVELOPMENT}

\section{Number of instars}

Although larvae were reared separately and given food ad libitum, the number of instars varied among the ten individuals surviving to pupation. Three reached pupation after completing five instars, six after six instars, and one after seven. Due to this variability in development, larval size could not be used to identify instar number (Figure 6).

\section{Development time}

For the eight individuals surviving to adulthood ${ }^{2}$, average development time, from oviposition to eclosion, was 80.9 days (range: $73-88$ days, s: 6.6 days, $N=8$ ). The amount of time spent in each stage by each individual is shown graphically in Figure 8 . The average time

${ }^{2}$ Of the remaining four, one died as a first instar, one sixth instar was killed for preservation, and two underwent poor pupations. 


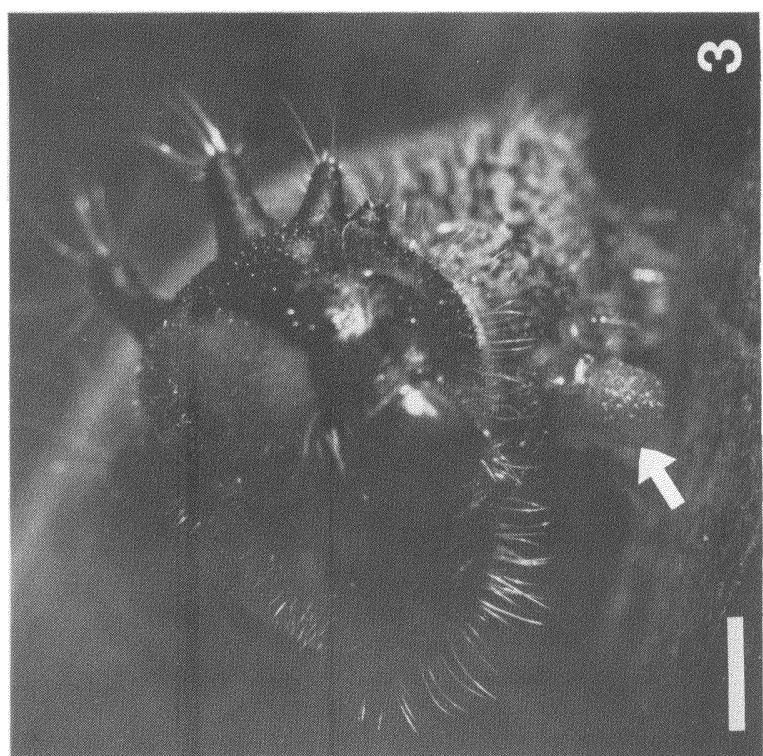

竞 


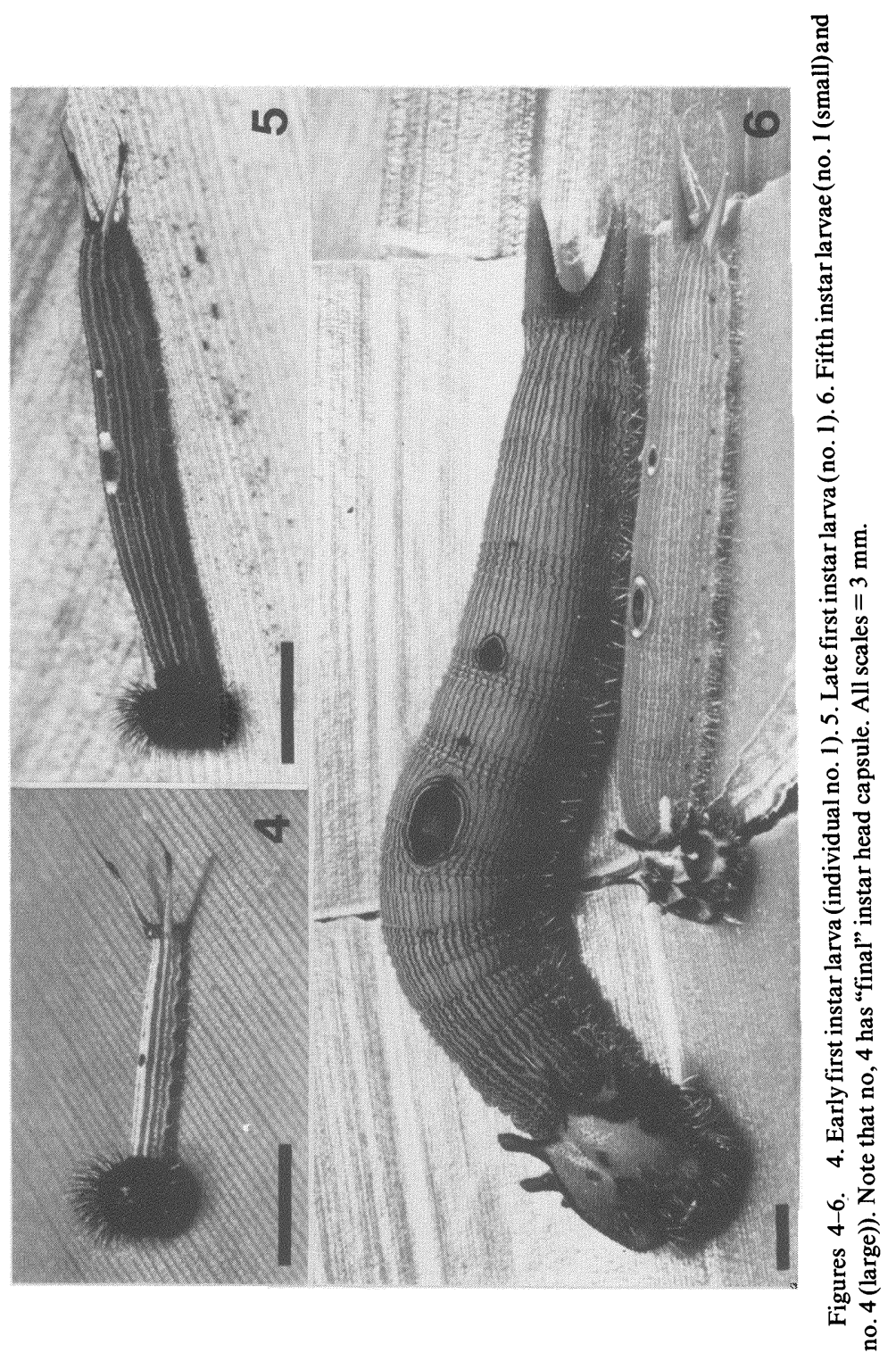




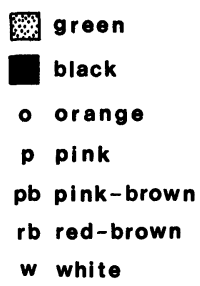

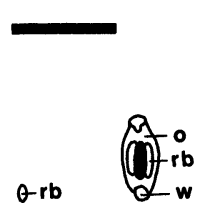

A

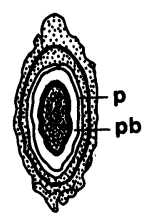

C

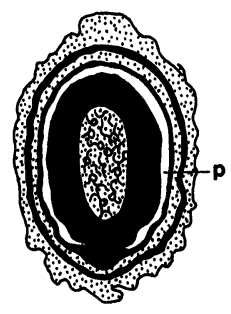

D

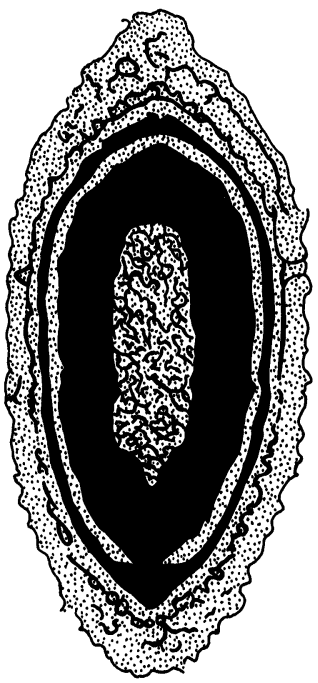

$E$

Figure 7. Dorsal spot at junction of abdominal segments 3 and 4. A: early first instar (individual no. 1); B: late first instar(no. 1); C: fourth instar(no. 8); D: early fifth instar (no. 4); E: late fifth instar (no. 12). Scale $=2 \mathrm{~mm}$.

spent in any given instar was 9.6 days (range 6-16 days, s: 2.4 days, $\mathrm{N}=63$ ). Every larva spent four days molting from each instar to the next: new cuticle formation occurred during the first two days, ecdysis took place on the thrid day, and by the end of the fourth day the new cuticle had hardened. No feeding took place during these four-day periods. These data reveal that the larvae were engaged in molting-related activities approximately $40 \%$ of the time, and feeding and resting $60 \%$ of the time.

\section{Head capsule}

Beginning with the second instar, the head bore four pairs of horns (Figure 9, C and D) radiating from it in a transverse plane perpendicular to the body axis. The larger and most dorsal two pairs were slightly expanded towards their rounded tips, while the smaller and more lateral two pairs were conical. The fine white simple setae which covered the head did not obscure pattern details. Setae on the horns were longer and projected from their tips. 


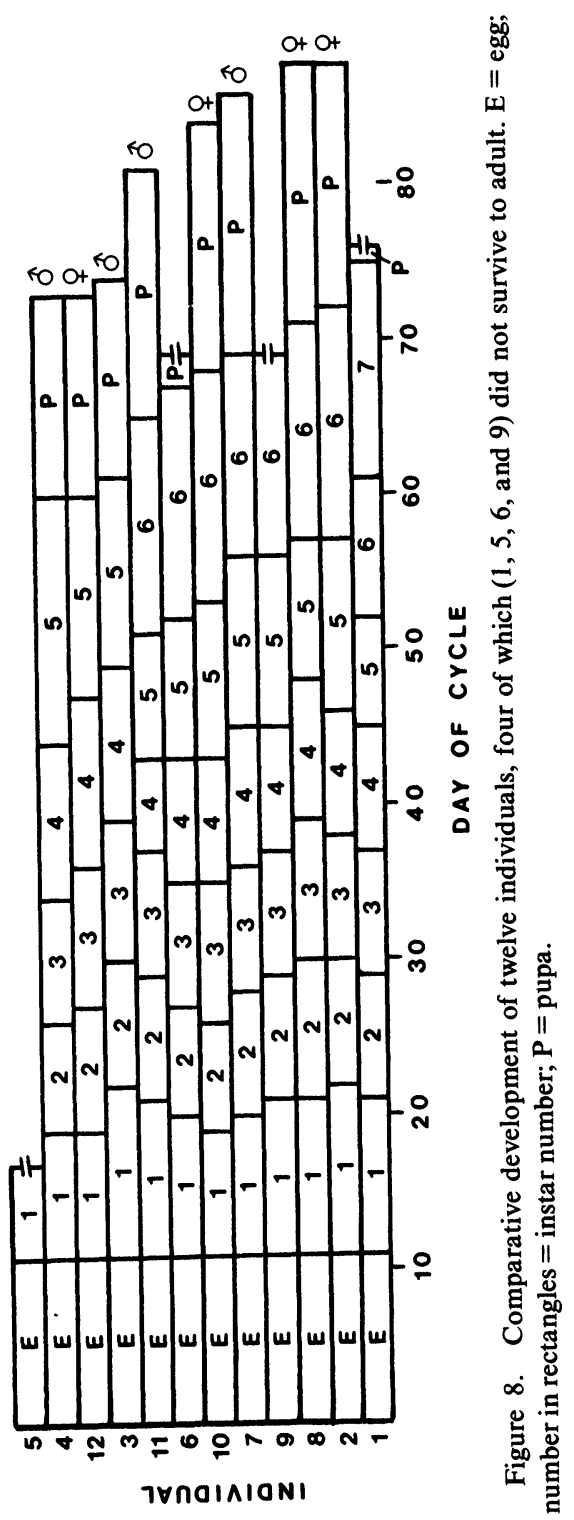


The complex beige, brown, and black head pattern of the second instar persisted through all succeeding instars except the final one. With the final instar, regardless of the number of previous instars, the head capsule took on a new, less complex pattern (Figure 9, E and F) of brown and black. All larvae which attained this new head pattern pupated at their next molt.

Head capsule widths, measured for all instars of each individual, indicate that size variation increased with each succeeding instar (Figure 10). However, the final instar, regardless of number (5th, 6th, 7th), showed slightly less size variation than did the next to last instar, suggesting that once a larva has reached a certain critical size it molts to the final instar, and from there to the pupa.

\section{Body}

With growth, the body colors underwent gradual change and additional stripes were added continually. The yellow and green stripes passed through a pale and dark green stage, and finally became dark brown and dark green. In mature larvae they anastomosed slightly.

The large dorsal spot changed from the pattern described for the first instar, to one with a greenish and black center, ringed with black, followed by pink-brown, pink, green, black (narrow), and green (Figure 7C). This pattern gave way to one with a black and green reticulated center, ringed with black (wide), pink (narrow), black (narrow), green (narrow), black (narrow), and green (medium) (Figure 7D). In mature larvae, the central black and green reticulate pattern was surrounded by a wide black ring, followed by rings of green, black, green, black (narrow and irregular), and green (wide) (Figure 7E).

The smaller dorsal spot also changed with growth. Gradually the anterior white portion expanded and encircled the black, and the center became reticulated black and white. By maturity the small spot had become an exact miniature of the larger one.

As larvae reached their full size, four smaller spots appeared, at the junctions of abdominal segments 1-2, 2-3, 4-5, and 6-7. Initially these spots were red-brown, but later changed to black. In addition, the nine pairs of spiracles showed as black spots along the sides of the body (prothorax, abdominal segments 1 through 8).

\section{Caudae}

From the second instar on, the caudae lacked apical setae, and 


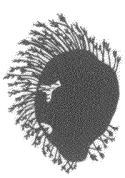

A

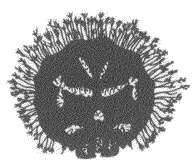

B

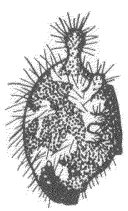

C

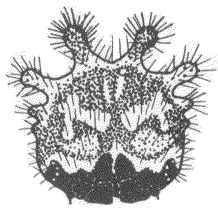

D
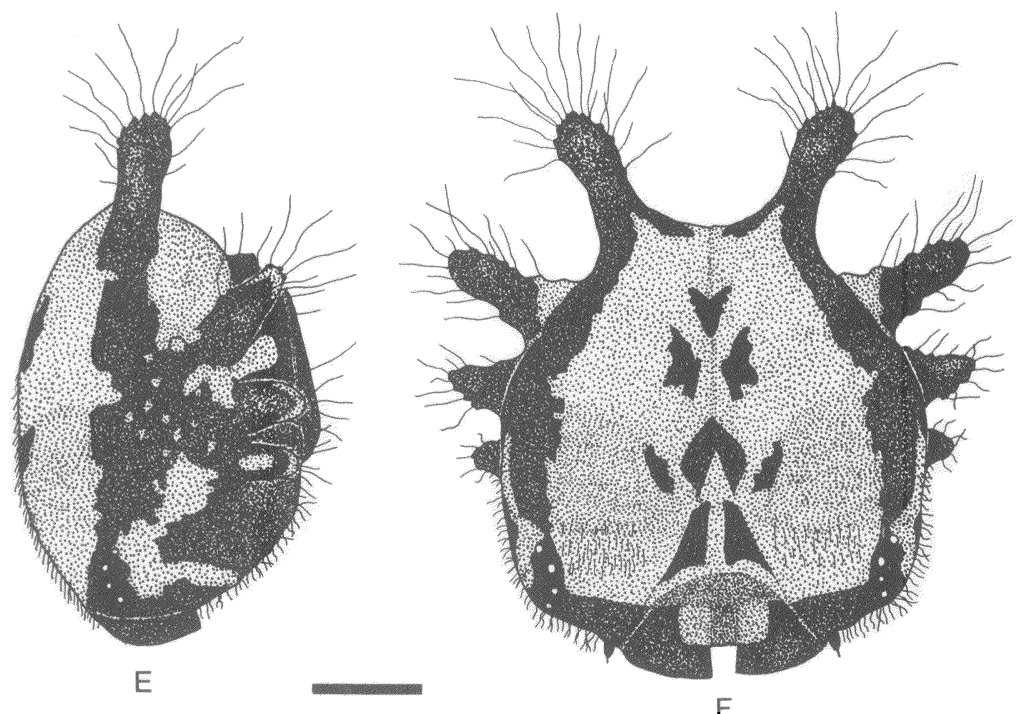

Figure 9. Head capsules of larva no. 3. Lateral (A, C, E) and frontal(B, D, F) views of instars one (A, B), two (C, D), and five $(E, F)$. Scale $=2 \mathrm{~mm}$.

were covered with short appressed setae. With growth the caudae became shorter in proportion to the body, and widened basally, approaching a conical shape in large larvae. Meanwhile, the black portion decreased until only the tips of the caudae were dark. The orange changed to red-brown and at last to dark brown, and the red area disappeared from the tip of the abdomen.

\section{Pupation}

Pupation and the processes leading to it took four days. During the first day, the larvae stopped eating, turned dark brown, emptied their guts, and shortened their bodies. The second day was spent crawling upon a support and spinning a silk stalk. During the third day, larvae grasped the stalk with their anal prolegs and hung upside down, and 


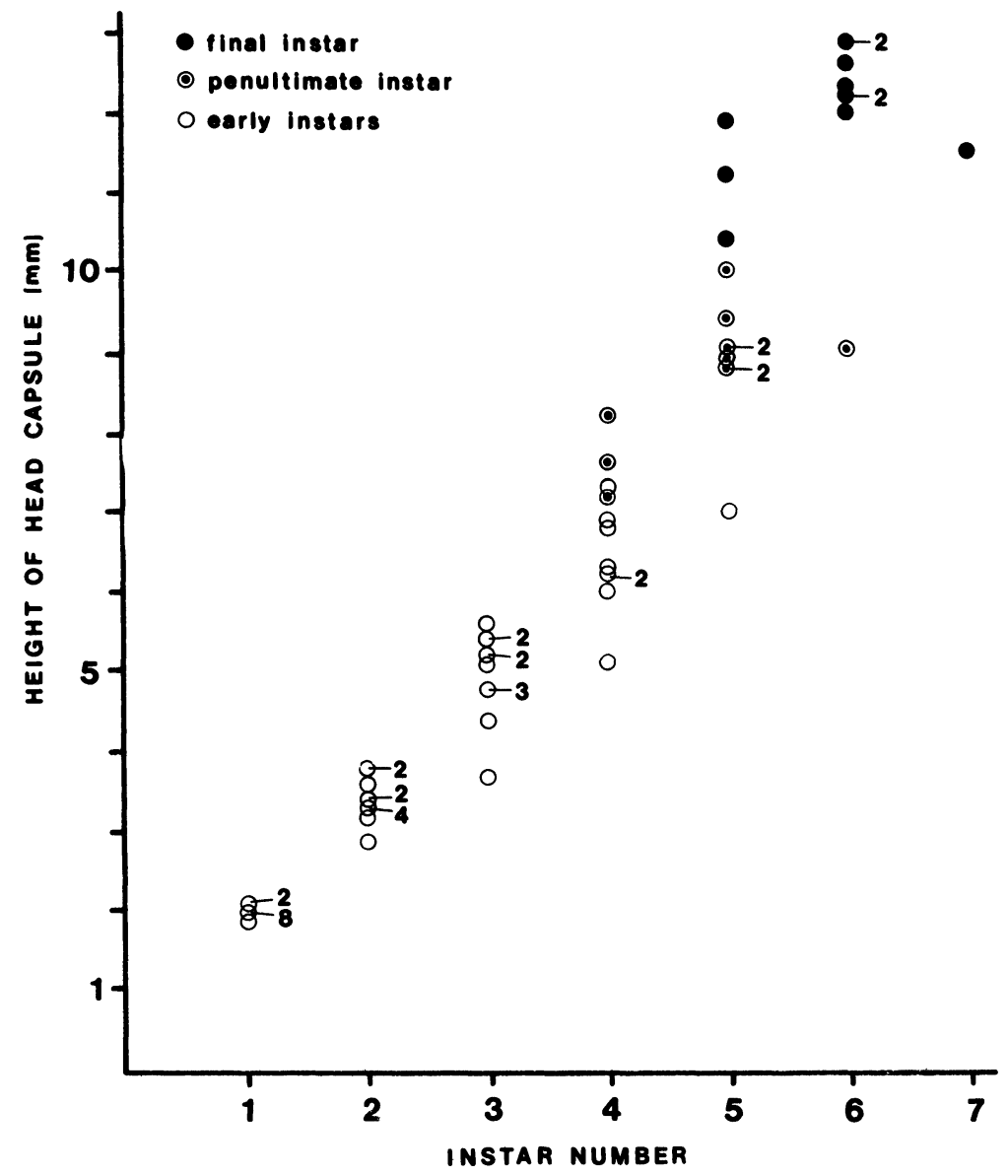

Figure 10. Heights of larval head capsules of each instar. Small numbers indicate frequencies greater than one.

on the morning of the fourth day they shed the last larval skin. By the evening of the fourth day, the pupae were hardened and darkened.

\section{Pupa}

Based on the eleven individuals available to us, the pupa (Figure 11) of Dynastor darius is about $4 \mathrm{~cm}$ long and bears a remarkable resemblance to the head of a snake. Its brown, beige, and whitish 


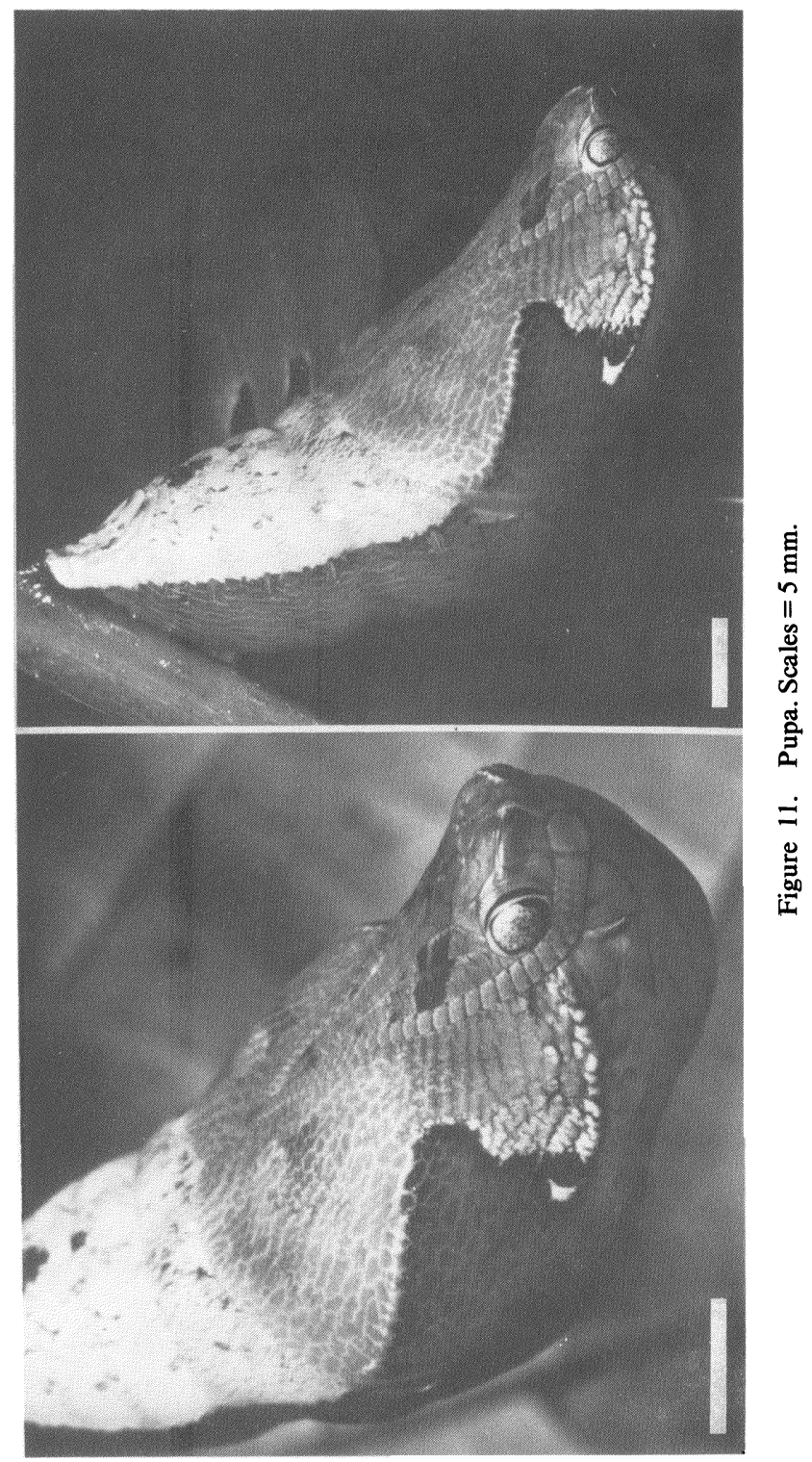


pattern, coupled with the constriction across the wings, the false scales beneath, the snake-like eyes (located where the true eyes of the adult butterfly will form), and large size give a very convincing illusion of snakeness, despite the fact that the eyes are in the "wrong" position for snake eyes. The question which arises when trying to understand such resemblances, is, "what good does it do to mimic a snake if, during those precious moments when your surprised predator hesitates, you cannot carry through by turning and running?" The answer may be that the predator itself turns and flees after suddenly coming face-to-face with a realistic "snake" that waves violently back and forth, as does the pupa of Dynastor darius when disturbed.

Like many brassoline pupae, the pupa of Dynastor darius has two lateral pairs of keels. The first begins on the outer margin of the wing very near the tornus, and runs across the wing perpendicular to the outer margin, ending at the edge of the discal cell. The second begins near the midpoint of the inner margin and follows that margin to the base of the wing.

The ground color of the pupa is whitish. The ventral side is irregularly striped with fine brown longitudinal lines which become more dense along a line following the spiracles. These lines fade into pseudo-reptilian scaling toward the anterior end of the pupa. Dorsally, the abdomen bears a complex brown pattern of fine lines and spots, which ends abruptly at its interface with the darker, ventral pattern.

The fore wings (concealing the hind wings) are covered with reticulations, which are beige except at the tornal angle where they are brown. The dark tornal angle lies between the keels and is marked off sharply from the rest of the wing by a dark brown line which begins at the midpoint of the inner margin (beginning of the second keel), runs perpendicular to it until reaching the end of the first keel, then turns sharply, following that keel to the outer margin where it joins the dark line which follows the spiracles.

The eye is beige with tiny black spots and is surrounded by a fine black line.

The pupal stage lasts an average of 15.1 days (range: $13-17$ days, s: 1.8 days, $\mathrm{N}=8$ ). The day before eclosion, the pupa turns dark brown. The dorsal pattern of the fore wings begins to show through the pupal integument several hours before emergence of the adult butterfly. 


\section{Discussion}

The life cycle

Burmeister's (1873) brief description and figure of a last instar larva of Dynastor darius from Rio de Janeiro agrees with our observations in all important respects, differing only slightly in details of the dorsal spots and the color of the head. The dorsal spots of Burmeister's larva were described as "oval eyes, black, with a yellowish pupil, surrounded by a white outer margin, bordered with black." It is not surprising that descriptions of the complex and ever changing dorsal spots would vary. The black and green reticulated center might be interpreted as dull yellow from a distance, the dark green or brown might be seen as black, and the outermost green rings, which blend with the pattern of the rest of the body could easily be overlooked. The head of Burmeister's specimen was "yellow-brown with a large dark maroon spot on each side immediately in front of the horns which are of the same color." His observations may have been made from a newly molted, partially darkened individual, or Brasilian specimens might be paler than Panamanian ones.

During a long visit to southern Brasil, Müller (1886) reared Dynastor darius from egg to adult, but did not describe the egg. His larva passed through five instars, the period from hatching to adult lasting 71 days. His detailed description notes changes in the dorsal spots and in the exact number of stripes present on the body. Our larvae showed considerable variation in number of body stripes among individuals of the same size. Müller's first instar was "redbrown and white," in contrast to ours which were red-brown and yellow. As did Burmeister, Müller also described the dorsal spots as having a yellow center. His pupa was "greenish white with very dense, fine, irregular long brown stripes." All eleven of our pupae were brown. Perhaps the pupal color varies geographically, genetically, or depends upon light conditions during or prior to pupation.

Rothschild (1916) briefly described and figured the last instar larva and pupa of Dynastor darius from an unpublished sketch by E. Hartgen, in the Tring Museum Library. The larva, as far as can be determined, was essentially the same as ours. Rothschild's figure of the "deep grass-green" pupa is difficult to interpret; the wings appear to cover the dorsal rather than the ventral side of the body. Being a figure from a sketch, perhaps something was lost in translation. 
None of these authors made reference to the snake-like appearance of the pupa. The resemblance may not be so obvious in green pupae.

\section{Ontogenetic variability}

With respect to the number of instars of Dynastor darius, the situation may be similar to that of Manduca sexta (Sphingidae). The larvae of $M$. sexta initiate the sequence of events leading to pupation at a critical weight, independent of the rate of growth (Nijhout and Williams, 1974a, 1974b). Like Manduca, Dynastor exhibits variability in the number of larval instars, corresponding with variability in growth rate, and it appears that the larvae commit themselves to pupation when a critical size is reached. In contrast to Manduca however, commitment in Dynastor may take place during the next to last instar, as evidenced by the fact that the final instar always has a head capsule pattern different from that of previous instars. Another possibility is that there may be two commitments: one to the final head capsule pattern, and another to pupation.

Preserved material (head capsules, pupal skins, adults, and larvae in alcohol) of Dynastor darius, upon which this study was based, labeled as Lots 78-75 (an individual collected as a pupa) and 78-84 (reared from eggs), has been deposited in the Museum of Comparative Zoology, Harvard University.

We would like to thank the Smithsonian Tropical Research Institute, Panama, for use of their facilities, Mr. Gary Stump for locating a wild pupa of Dynastor darius on BCI, Mr. Nigel Franks for assisting with rearing, Mr. Gordon B. Small for identification of the butterfly, and Mr. Norman Woodiey for reading the manuscript.

\section{REFERENCES}

Blandin, P.

1976. La distribution des Brassolinae (Lepidoptera-Satyridae). Faits et problèmes. pp. 161-218. In H. Decimon, ed., Biogeographie et Evolution en Amerique Tropicale, Publ. Lab. Zool. de l'Ecole Normale Superieure No. 9.

Blandin, P. and Descimon, H.

1977. Contribution a la connaissance des Lépidoptères de l'équateur. Nouvelles données sur les Brassolinae [Nymphalidae] de l'occidente. Annls. Soc. ent. Fr., (N.S.) 13: 75-88.

BURMEISTER, H.

1873. De Morphonides Brésiliens. Rev. Mag. Zool. Pure et Appl., (3)1: 17-47. 
MÜller, W.

1886. Südamerikanische Nymphalidenraupen Versuch eines natürlichen Systems der Nymphaliden. Zoologische Jahrbücher. Zeitschrift für Syst. Geogr. Biol. Thiere, 1: 417-678.

Nijhout, H. F. and Williams, C. M.

1974a. Control of moulting and metamorphosis in the tobacco hornworm, Manduca sexta (L.): growth of the last-instar larva and the decision to pupate. J. Exp. Biol., 61: 481-491.

1974b. Control of moulting and metamorphosis in the tobacco hornworm, Manduca sexta (L.): cessation of juvenile hormone secretion as a trigger for pupation. J. Exp. Biol., 61: 493-501.

RoTHSCHILD, L.

1916. Notes on Amathusiidae, Brassolidae, Morphidae, etc., with descriptions of new forms. Novit. Zool., 23: 299-318. 

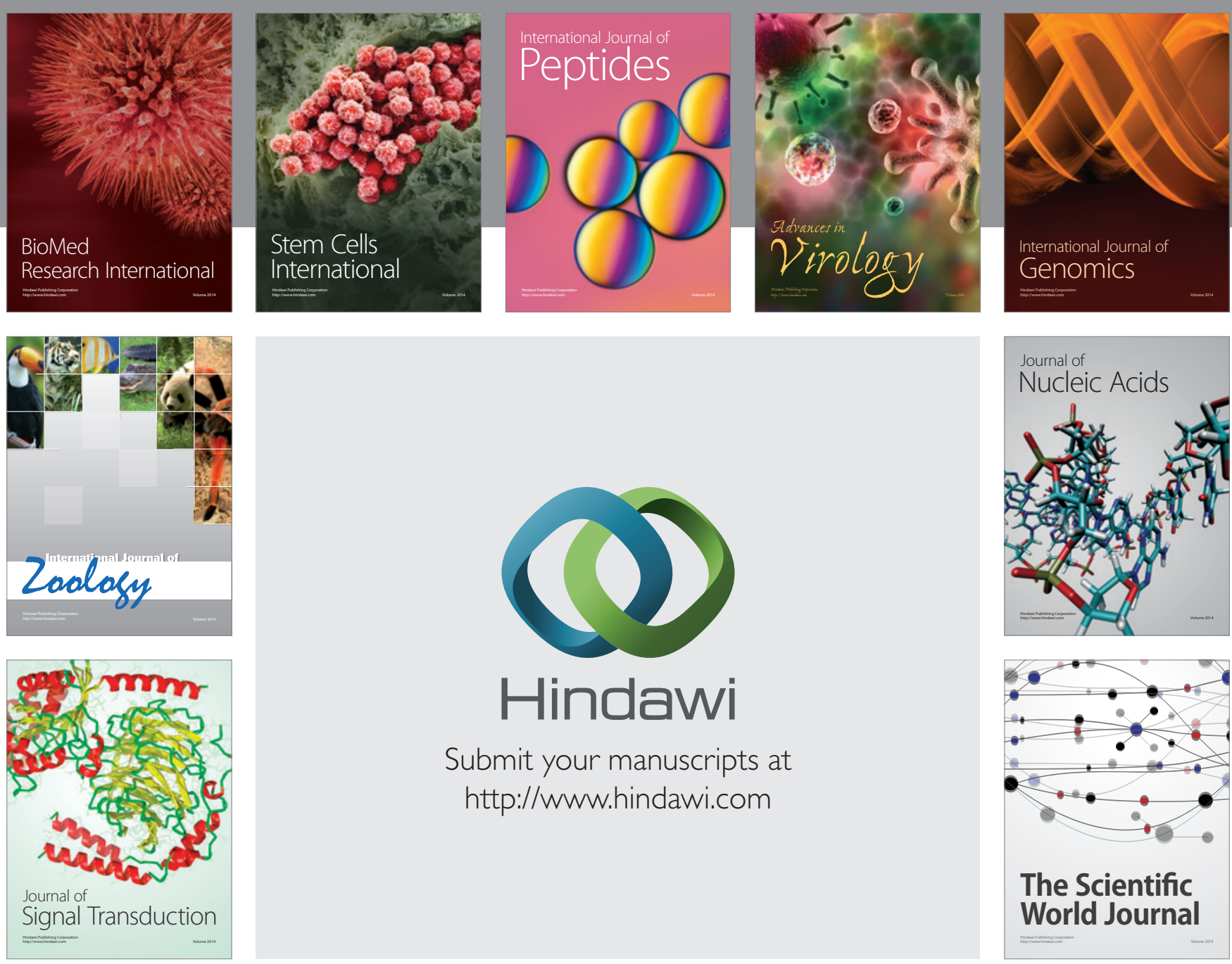

Submit your manuscripts at

http://www.hindawi.com
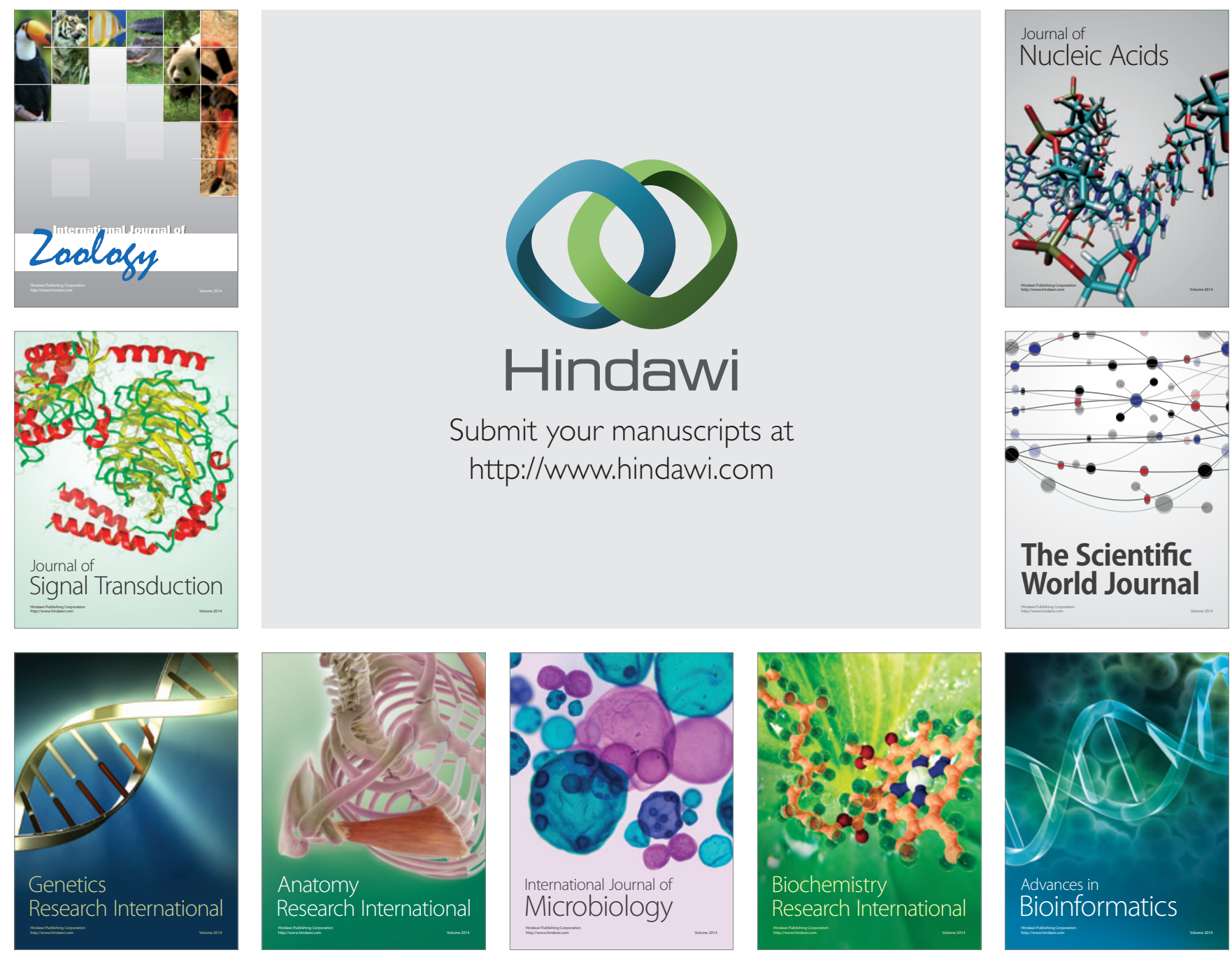

The Scientific World Journal
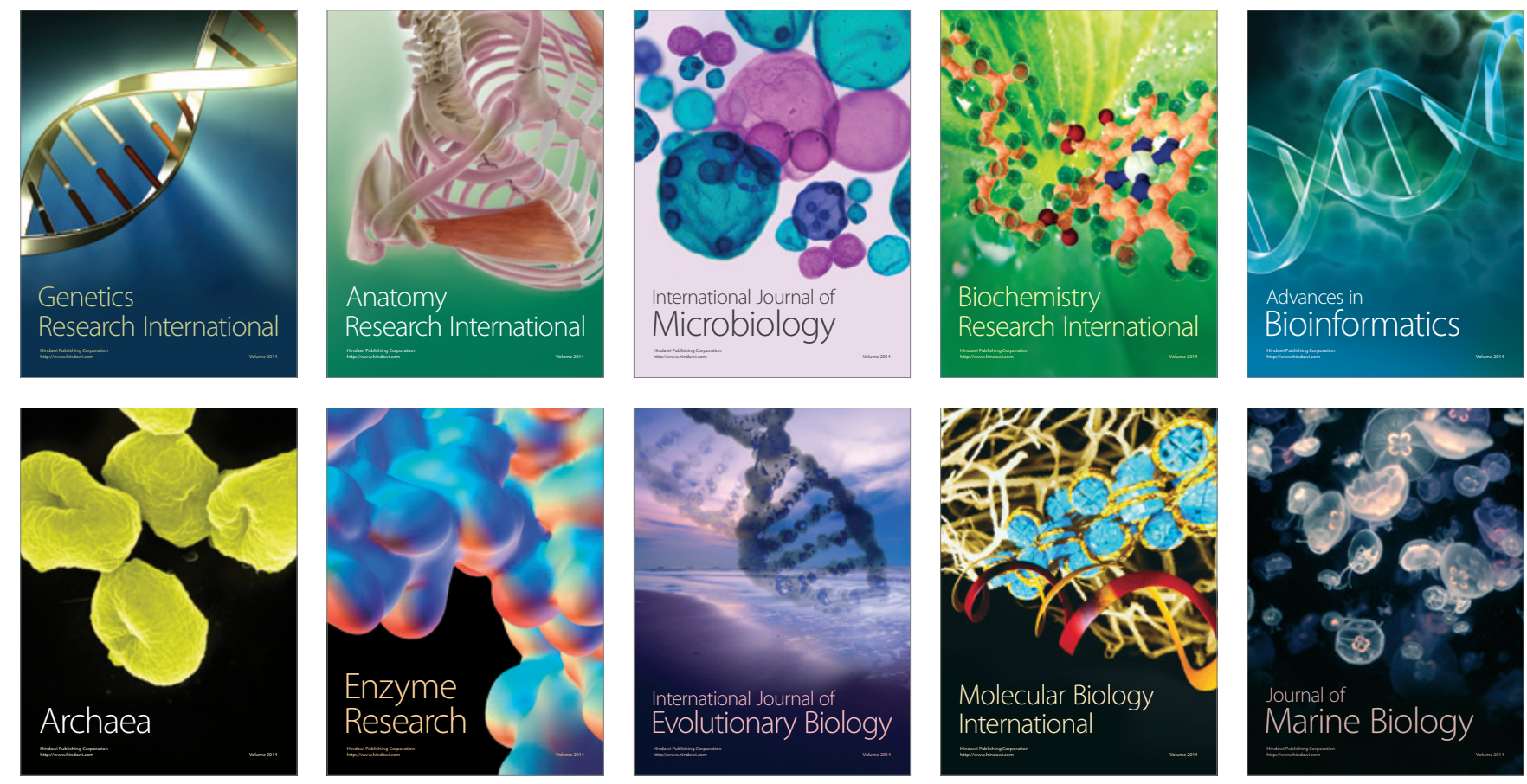